\title{
How I Write
}

\section{Kate Holden}

I kNOw I must be a writer because I have procrastinated writing this piece for weeks, promised myself that I'll sit and properly cogitate it before I lay finger to keyboard, promised I'll make a list of what I want to say, and yet here I am, throwing myself onto the page before I've had a thought in my head. That's how I write. For me, writing is all about a high-wire act: keeping the nerve. The nerve is the thing. Hold the poise, one step or word after another, and don't look down til the end.

Writing is the most incredible act of daredevilry and it doesn't do to think about it too much. My writing is a mystery to me. When it's going well I basically take dictation from the voice in my head; as long as I have a vague notion of what I want to say, the words find themselves. I consider this a gift from the writing gods (cat-shaped, inscrutable totems with eyes you can't stare at too long) and try not to question it. When I question, I lose all my nerve and the words won't come, or are all quite astoundingly repulsive.

Much of writing, in my belief, is waiting. I wait a lot. Sometimes weeks or months, while thoughts slowly percolate and drip into place. I've discovered the efficacy of putting off a novel for several years; by the time you finally allow yourself to have a go, it's no longer toil, it's a treat. And I rehearse lines in my head-as I do the washing up, sit on a train, walk around the block, daydream in the morning before I get up-until I at least have a first line to start with. When I'm feeling sharp I realise I am phrasing descriptions of almost everything that happens to me, almost as instantly as I experience them. Obsessive and weird, sure, but helpful.

I work on various things and in various ways but I am always fast, I'm 
grateful to say. In addition to two memoirs and two unpublished novels, I write feature articles, frequently answer interview questions, tried my hand at a short play, and have the great gift/terror of a fortnightly newspaper column.

This last is my cardio exercise, compared to the weight-bearing endorphins-blast of the other works. A column takes speed, brio and impetus, and I am amazed to realise that I have now penned nearly a hundred and fifty of them, each one a discrete mini-essay contained in around 800 words. The form and length is now familiar to me so I can turn it as neatly as a sonnet, but each fortnight as I face that blank screen I experience the inevitable panic and sense of hubris. Who am I and why the hell do I think anyone wants to know what I think? Hence the need for nerve, until I email it off with my eyes clenched shut and it's not my problem anymore. Think of it like a sprint on a tightrope. It's invigorating, that's the least of its joys.

One thing I've learned is to allow plenty of time for my procrastination, but still aim to finish something well before deadline. That way my 'edge' about writing won't collapse into fully fledged panic about not getting it in. The procrastination and the sinking into doubt and the finicky editing is all built into my timeline. There are few things worse than genuinely running out of time and having to submit something you know isn't properly cooked.

Longer works I can also write quickly. There's nothing like the rush of a first draft. I can work up a full first draft in a month. Every morning when I'm working on one I fumble blindly over the contours of the previous day's work for a few minutes, teeter at the vertiginous edge of the lastwritten paragraph, and then dive forwards. Like Indiana Jones found in The Last Crusade, what looks like a terrifying chasm actually has an invisible bridge across to the other side.

I don't know what I enjoy more, the initial draft in all its mystery and thrill or the luxurious scraping down of the text afterwards. I love making sentences-I confess, I can caress and admire my own writing-but I am a bad rewriter. I can delete but it's almost beyond me to change a text beyond fiddling with word choice, punctuation, syntax and ripping out great chunks. Nevertheless, it's an almost erotic feeling, raking and shaking and pressing down a piece of work into a tighter, fitter, leaner 
shape. Work is never finished but it can always improve. That's why I love, adore, cherish and am occasionally frightened of editors.

Almost always I feel distant from my writing almost as soon as it's left my fingers. Sometimes I have no memory of writing a piece, and often I view my work as a phenomenon I simply have custody of. Then I recollect the satisfaction of having chosen that adjective, removed that adverb, rearranged the clauses of that sentence, and I can claim a little-mostly the errors and weaknesses-as my own.

Of course I welcome criticism; and of course I don't really care for it. So I'm outside the writing, and then, when prodded, very definitely inside it, baring my teeth.

My most dreadful fear is not of writing badly but of missing the golden subject, 'the one'. I keep notebooks, but they catch only a snippet of all my thoughts and the wonders I observe and the conversations I have and the facts I learn and the anecdotes I marvel at. There's too much in the world, a writer hurtles past it, and can only hope that her butterfly net has caught a little as she speeds. 